\title{
Randomized trial of paroxetine in end-stage COPD
}

\author{
Y. Lacasse1, L. Beaudoin2, L. Rousseau², F. Maltais1
}

ABSTRACT: Randomized trial of paroxetine in end-stage COPD. Y. Lacasse, L. Beaudoin, L. Rousseau, F. Maltais. Background: Although the underlying pathology is initially confined to the lungs, the associated emotional responses to chronic obstructive pulmonary disease (COPD) contribute greatly to the resulting morbidity. The objective of this study was to examine the effect of an antidepressant drug on disease-specific quality of life in patients with end-stage COPD who present significant depressive symptoms.

Methods: We conducted a 12-week, randomized double-blind placebo-controlled trial of Paroxetine in which quality of life measured by the Chronic Respiratory Questionnaire (CRQ), an evaluative COPD-specific quality-oflife questionnaire, was the primary outcome.

Results: 23 patients were randomized and 15 completed the trial (8 on Paroxetine; 7 on placebo). In the per-pro- tocol analysis, we observed statistically and clinically significant improvements favoring the active treatment in 2 of the 4 domains of the CRQ: emotional function (adjusted mean difference: 1.1 ; 95\% confidence interval [CI]: 0.0 - 2.2) and mastery (difference: 1.1; CI: 0.4 - 1.8). Dyspnea and fatigue improved, but to an extent that did not reach statistical significance. In the intention-to-treat analysis, none of the differences in CRQ scores was significant. Paroxetine was not associated to any worsening of respiratory symptoms.

Conclusions: The results of this small randomized trial indicated that patients with end-stage COPD may benefit from antidepressant drug therapy when significant depressive symptoms are present. This study underlined the difficulties in conducting experimental studies in frail and elderly patients with COPD.

Monaldi Arch Chest Dis 2004; 61: 3, 140-147.

Keywords: COPD, depression, antidepressant drug, Paroxetine, randomized trial.

1 Centre de recherche, Centre de Pneumologie, Hôpital Laval, Institut universitaire de cardiologie et de pneumologie de l'Université Laval, Québec, Canada.

2 Service régional des soins respiratoires spécialisés à domicile, Québec, Canada.

3 Département de Psychiatrie, Hôpital Laval, Institut universitaire de cardiologie et de pneumologie de l'Université Laval, Québec, Canada.

Correspondence: Dr. Yves Lacasse; Centre de Pneumologie; Hôpital Laval; 2725 Chemin Ste-Foy; Ste-Foy, Quebec; G1V 4G5; Canada; e-mail: Yves.Lacasse@med.ulaval.ca

Supported by The Quebec Lung Association. The active drug was supplied by Glaxo SmithKline who was not otherwise involved in the study design or the data analysis. Yves Lacasse is a clinician scientist and François Maltais is a research scholar of the Fonds de la recherche en santé du Québec.

\section{Introduction}

More than 750.000 Canadians have been told by a health professional that they suffer from chronic obstructive pulmonary disease (COPD) [1]. Although the underlying pathology is initially confined to the lungs, the associated physical deconditioning and the emotional responses contribute greatly to the resulting morbidity. Increased shortness of breath leads to inactivity and consequent physical deconditioning, which in turn leads to further inactivity, social isolation, fear of dyspnea and depression [2]. In a cross-sectional survey of COPD patients on long-term oxygen therapy, we found that $57 \%$ of our patients demonstrated significant depressive symptoms; in addition, $18 \%$ were severely depressed [3]. Only $6 \%$ of those patients who met the criteria for depression were taking an antidepressant drug. This represented strong evidence that depression is under-recognized and under-treated in this group of patients.
Respiratory rehabilitation is gaining wider acceptance [4], as reports of its effectiveness begin to address the physiologic bases of exercise training [5,6], and randomized controlled trials include rigorous measures of health-related quality of life [7]. Unfortunately, the barriers to rehabilitation are numerous. The access to rehabilitation programs is limited [8] and is further reduced by several contra-indications to exercise training and exclusion criteria to rehabilitation programs [4]. Exclusion criteria in controlled clinical trials of comprehensive respiratory rehabilitation in COPD consisted of ischemic heart disease, heart failure, intermittent claudication, disabling musculoskeletal disorders and other medical conditions limiting exercise tolerance. Also, elderly patients with far-advanced COPD may not be able to fully participate in an exercice program.

Many patients with COPD are hence left without any therapy directly aimed at the improvement of emotional functions. This study was designed to investigate the effect of a 12-week trial of an anti- 
depressant drug on the health-related quality of life of patients with end-stage COPD not otherwise amenable to rehabilitation.

\section{Methods}

\section{Clinical setting and patients}

The trial took place within the Quebec City Respiratory Home Care Service. This service is affiliated to our hospital and delivers home care (mainly long-term oxygen therapy and related services) to patients with any chronic lung disease who must be registered to the program. Out-patients aged $\geq 60$ with a diagnosis of COPD supported by an history of past or current smoking, and an FEV $1 \leq 50 \%$ of predicted value were eligible to the study. All were on long-term oxygen therapy ( $\geq$ 18 hours a day). Significant depressive symptoms must have been present at randomization. We used the Geriatric Depression Scale (GDS) as a casefinding questionnaire for significant depressive symptoms and depression [9]. The GDS is a 30yes-no-item questionnaire that represents a reliable and valid depression screening scale for elderly populations [10]. A score $\geq 11 / 30$ indicates significant depressive symptoms [10]; a score $\geq 20 / 30$ indicates severe depression. The ability to give informed consent was mandatory. We excluded from the trial patients with contra-indication to antidepressant drug therapy (known hypersensitivity to the active drug, or recent use [ $\leq 2$ weeks] of a monoamine oxydase inhibitor), current or recent antidepressant or neuroleptic drug therapy (within the last 3 months) or current participation in a respiratory rehabilitation program. The study protocol was approved by our local ethics committee.

\section{Intervention}

The choice of the antidepressant drug was based on the requirements of any drug to be used in elderly patients. The ideal antidepressant would have a low side-effect profile, a relatively short half-life, and no active metabolites. It would provoke few drug interactions and could be given once or twice a day [11]. Also, the choice of the antidepressant was based on the typical pattern of depression in patients with chronic respiratory diseases who are more likely to present low self-esteem, high apathy [12] and a high level of anxiety. Therefore, we sought to select an antidepressant drug with anxiolytic properties. Paroxetine (Paxil®, Glaxo SmithKline, Mississauga, Ontario, Canada) was found to meet the above-mentioned requirements. It belongs to the category of new highly selective serotonin-reuptake inhibitors [13]. Paroxetine was started at the dose of $5 \mathrm{mg}$ OD, with weekly 5-mg increments up to a maximum of $20 \mathrm{mg}$ OD or the highest dose not associated with any side effect.

\section{Measures and outcomes}

Primary outcome: The change in score in the "emotional function" domain of the Chronic Res- piratory Questionnaire (CRQ) at 12-week followup represented the primary outcome of this trial [14]. The CRQ is a disease-specific, intervieweradministered instrument that measures, in addition to emotional function, patients' dyspnea, fatigue, and mastery (the extent to which they feel they can cope with the disease and its manifestations). Each domain includes 4 to 7 items and each item is scored on a 7-point scale. When the CRQ has been used to evaluate treatment, all four domains have performed well in detecting small treatment effects [15]. Differences in CRQ scores of 0.5, 1.0 and 1.5 correspond to small but important, moderate, and large treatment effects, respectively [16].

Baseline assessment of quality of life: We selected the Medical Outcome Survey - Short Form 36 (SF-36) [17] as a questionnaire to characterize the patients at baseline. The SF-36 is a generic questionnaire that measures 8 dimensions of health: physical functioning, role limitation due to physical problems, role limitation due to emotional problems, social functioning, mental health, energy/vitality, bodily pain and general health perceptions. SF-36 items and scales are scored so that a higher score indicates a better health state. We administered the validated French version of the questionnaire [18] which we currently use in our respiratory rehabilitation program.

Assessment and report of adverse effects: At each follow-up visit, the patients were presented a checklist of potential side effects and asked to identify any new effect. Also, they were allowed to report at anytime any troublesome side effect either to their attending home-care nurse or to the research assistant. A decision whether to withdraw the patient from the trial was then made by the principal investigator.

Compliance to drug regimen: Compliance to drug regimen was ascertained by monitoring pills count at each visit.

\section{Study protocol}

Following our survey [3], patients with significant depressive symptoms were identified. Eligibility was first ascertained by a pulmonologist (YL or FM) and a psychiatrist (LR). The patient's family physician was notified of the screening of his/her patient for a trial of antidepressant drug. The family physician could deny his/her patient's participation to the trial in case of severe depression requiring the immediate initiation of antidepressant drug therapy. The patients' baseline evaluation, the initiation of the medication and all the follow-up visits took place at the patients' home and were under the supervision of a registered nurse (LB) knowledgeable of the area of home care in COPD. A random numbers table was used to allocate the patients to receive either Paroxetine or an identical placebo. The randomization process was under the responsibility of one of the hospital pharmacists who was not otherwise involved in the trial. The CRQ was 
administered at baseline and at 4-, 8- and 12-week follow-up. Following the trial, the patients were referred to their family physician who could write a prescription of Paroxetine, without knowledge of the drug received during the trial.

\section{Statistics}

Sample size: The differences in CRQ scores that correspond to small but important, moderate, and large treatment effects allowed us to compute sample sizes according to the magnitude of the treatment effect to be detected [15]. Sample sizes of 9,18 and 63 patients per group were needed to detect large, moderate, and small but important treatment effects respectively, with a power of $80 \%$ and a type I error of 0.05 (two tailed).

Statistical analysis: Baseline characteristics were compared between groups using unpaired ttests for continuous variables and Fisher's exact tests for the categorical variables. Changes in CRQ scores in both groups were analyzed in two ways. First, in a per-protocol (efficacy) analysis, we analyzed the data of the patients who completed the study. In addition to the within-group differences, we calculated 95\% confidence intervals (CI) around the mean differences between the two groups at final follow-up (adjusted for baseline differences). A second analysis based on the intention-to-treat principle was also conducted. In this analysis, those patients who received the active drug and who dropped out during the trial were given the worse score possible on the questionnaires, whereas those who were on placebo were given the best possible scores [19]. The prevalence of side effects related to drug therapy was analyzed as discrete variables and was compared between groups using Fisher's exact tests. The level of significance was set at 0.05 (two sided).

\section{Results}

\section{Population}

The trial profile is depicted in figure 1 . The trial was stopped prematurely because of difficulties in patients accrual. 342 patients were screened; 105 were deemed eligible. Twenty-three were randomized; 15 completed the trial. The reasons for exclusion and discontinuation are included in figure 1 . Table 1 summarizes the baseline characteristics of those who were randomized. On average, the patients had depressive symptoms of moderate intensity. Table 2 summarizes the results of the quality-of-life assessment at baseline. In comparison to normative data, the patients' general quality of life was severely impaired. There was no significant difference in the baseline characteristics between the subjects of both groups and between those who completed and those who did not complete the trial.

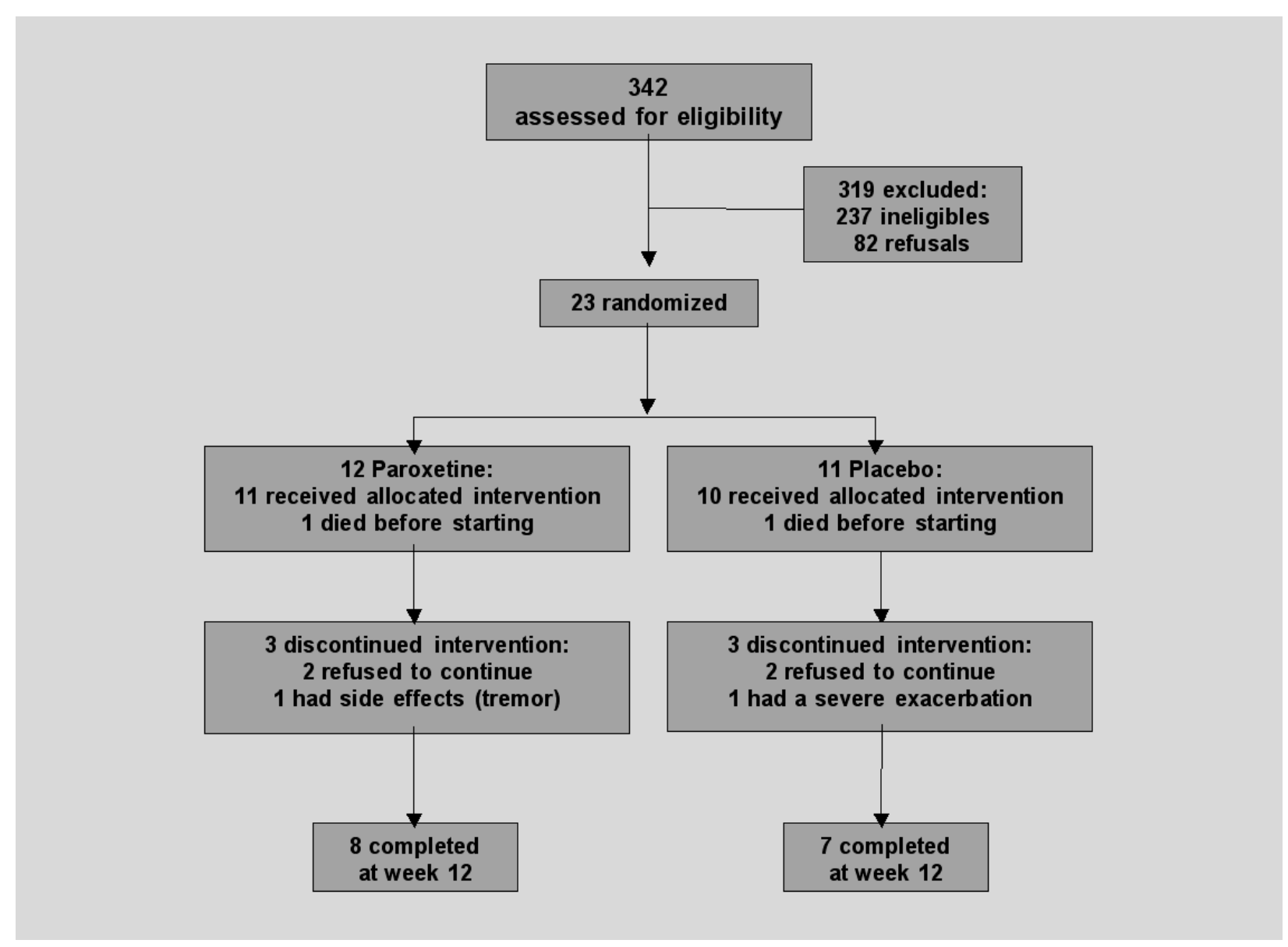

Fig. 1. - Trial profile. 
Table 1. - Baseline clinical characteristics of the patients who entered the study $(n=23)$

\begin{tabular}{|c|c|c|c|}
\hline Characteristics & $\begin{array}{l}\text { Paroxetine } \\
(\mathbf{n}=12)\end{array}$ & $\begin{array}{l}\text { Placebo } \\
(\mathbf{n}=11)\end{array}$ & $P$ value \\
\hline Gender (M/F) & $5 / 7$ & $5 / 6$ & 0.8 \\
\hline Age (years, mean, SD) & $71.2(8.4)$ & $69.8(7.6)$ & 0.8 \\
\hline $\mathrm{FEV}_{1}(\%$ pred, mean, $\mathrm{SD})$ & $32.4(14.9)$ & $36.8(14.3)$ & 0.4 \\
\hline $\mathrm{PaO}_{2}(\mathrm{mmHg}$, mean, $\mathrm{SD})$ & $52.3(6.7)$ & $59.9(10.9)$ & 0.1 \\
\hline $\mathrm{PaCO}_{2}(\mathrm{mmHg}$, mean, $\mathrm{SD})$ & $46.9(4.9)$ & $49.3(7.9)$ & 0.5 \\
\hline $\begin{array}{l}\text { Past medical history (number of major } \\
\text { medical diagnoses, excluding COPD*; } \\
\text { (median, min-max) }\end{array}$ & $0(0-2)$ & $1(0-2)$ & 0.3 \\
\hline $\begin{array}{l}\text { Time since the introduction of long-term oxygen } \\
\text { therapy (months, mean, SD) }\end{array}$ & $27.9(14.9)$ & $28.3(34.6)$ & 0.3 \\
\hline Living with spouse $(\%)$ & 66.7 & 63.6 & 0.6 \\
\hline $\begin{array}{l}\text { Number of drug prescriptions } \\
\text { (median, min-max) }\end{array}$ & $8(5-13)$ & $7(4-17)$ & 0.3 \\
\hline Geriatric Depression Scale score (mean, SD) & $18.7(3.6)$ & $17.9(5.2)$ & 0.6 \\
\hline
\end{tabular}

Table 2. - Baseline generic and disease-specific quality-of-life scores

\begin{tabular}{|c|c|c|c|c|}
\hline & $\begin{array}{l}\text { Paroxetine } \\
(\mathbf{n}=12)\end{array}$ & $\begin{array}{l}\text { Placebo } \\
(\mathrm{n}=11)\end{array}$ & $P$ value & Normative data* \\
\hline \multicolumn{5}{|l|}{$S F-36$} \\
\hline - physical functioning & $18.6(10.0)$ & $19.0(9.9)$ & 0.9 & 75.7 \\
\hline - role physical & $43.2(35.5)$ & $25.0(23.6)$ & 0.2 & 76.2 \\
\hline - role emotional & $63.6(34.9)$ & $63.3(36.8)$ & 1.0 & 83.4 \\
\hline - social functioning & $55.9(19.0)$ & $41.5(18.6)$ & 0.1 & 87.0 \\
\hline - bodily pain & $59.3(29.3)$ & $65.9(26.2)$ & 0.6 & 74.0 \\
\hline - mental health & $53.1(23.2)$ & $58.0(16.8)$ & 0.4 & 79.3 \\
\hline - vitality & $39.5(16.7)$ & $40.0(17.8)$ & 0.9 & 67.7 \\
\hline - general health perception & $28.7(16.4)$ & $29.8(16.4)$ & 0.8 & 73.5 \\
\hline \multicolumn{5}{|c|}{ Chronic Respiratory Questionnaire } \\
\hline - emotional function & $3.5(0.9)$ & $3.7(1.0)$ & 0.8 & - \\
\hline - mastery & $4.3(1.0)$ & $4.9(0.9)$ & 0.2 & - \\
\hline - dyspnea & $3.4(0.9)$ & $3.4(0.6)$ & 1.0 & - \\
\hline - fatigue & $3.6(0.8)$ & $3.2(1.1)$ & 0.3 & - \\
\hline
\end{tabular}

* Age- $(65$ - 74) and sex-standardized scores for the 8 domains of the SF-36; from reference [20].

\section{Compliance}

With the exception of one patient in the treatment group, all the patients were compliant to their drug regimen according to the pill count. Six of the 8 patients on Paroxetine reached the maximal dose of $20 \mathrm{mg} \mathrm{OD}$ at the fourth week of treatment. The other two patients did not tolerate the maximal dose and were treated with $10 \mathrm{mg}$ OD.

\section{Chronic Respiratory Questionnaire}

The unadjusted changes in CRQ scores at final follow-up are presented in figure 2 . In the per-protocol analysis, despite the small number of patients who completed the trial, we observed statistically and clinically significant improvement favoring the active treatment in the "emotional function" domain (adjusted mean difference: $1.1 ; 95 \%$ confidence interval [CI]: $0.0-2.2)$ and "mastery" domain (difference: $1.1 ; 95 \% \mathrm{CI}$ : $0.4-1.8$ ) of the CRQ. In both domains, the adjusted mean difference between the two groups exceeded the minimal clinically important difference (figure 3). Dyspnea and fatigue improved, but to an extent that did not reach statistical significance. In the more conservative intention-totreat analysis, the adjusted mean difference in score between the two groups at final follow-up did not reach the level of statistical significance for both the "emotional function" and "mastery" domains of the CRQ. 


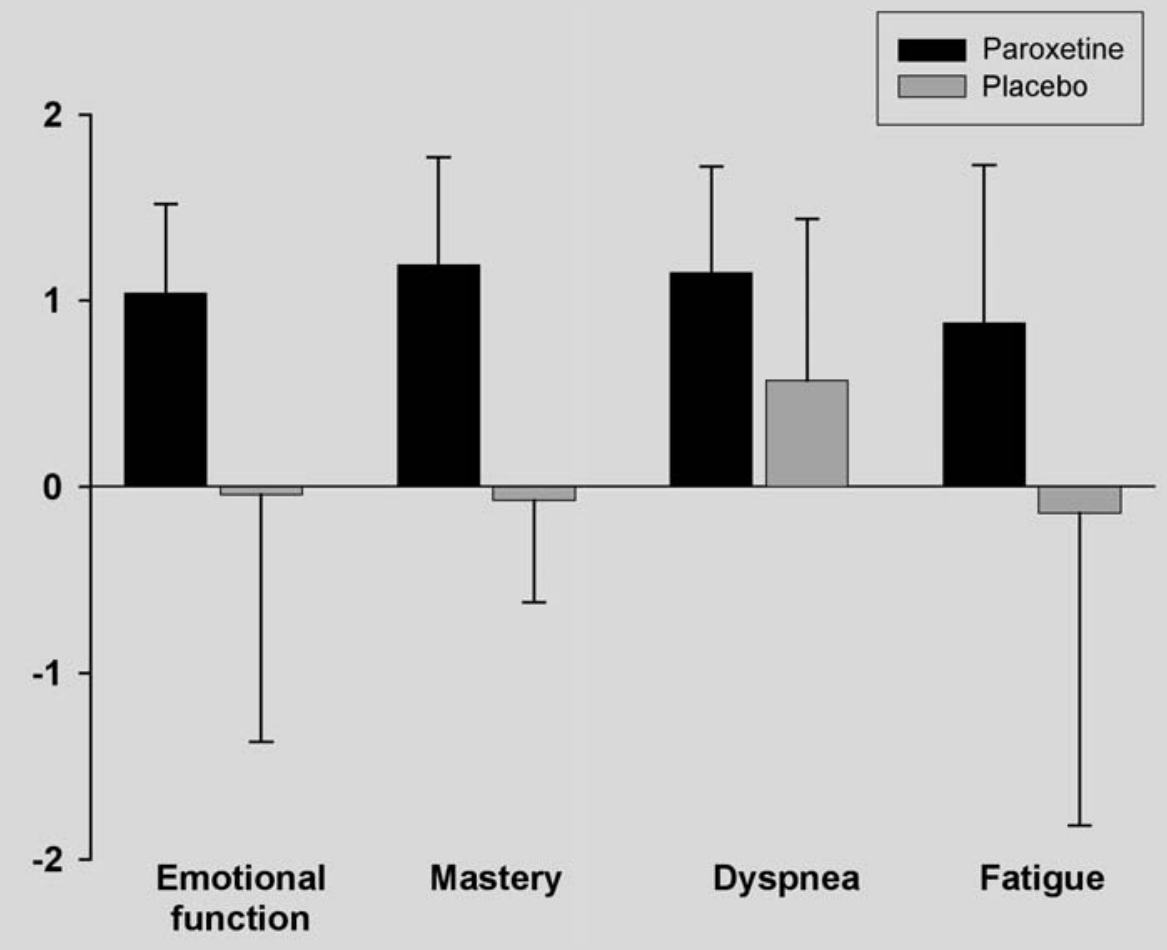

Fig. 2. - Within-group differences in CRQ scores. The means and standard deviations are unadjusted for baseline imbalances.

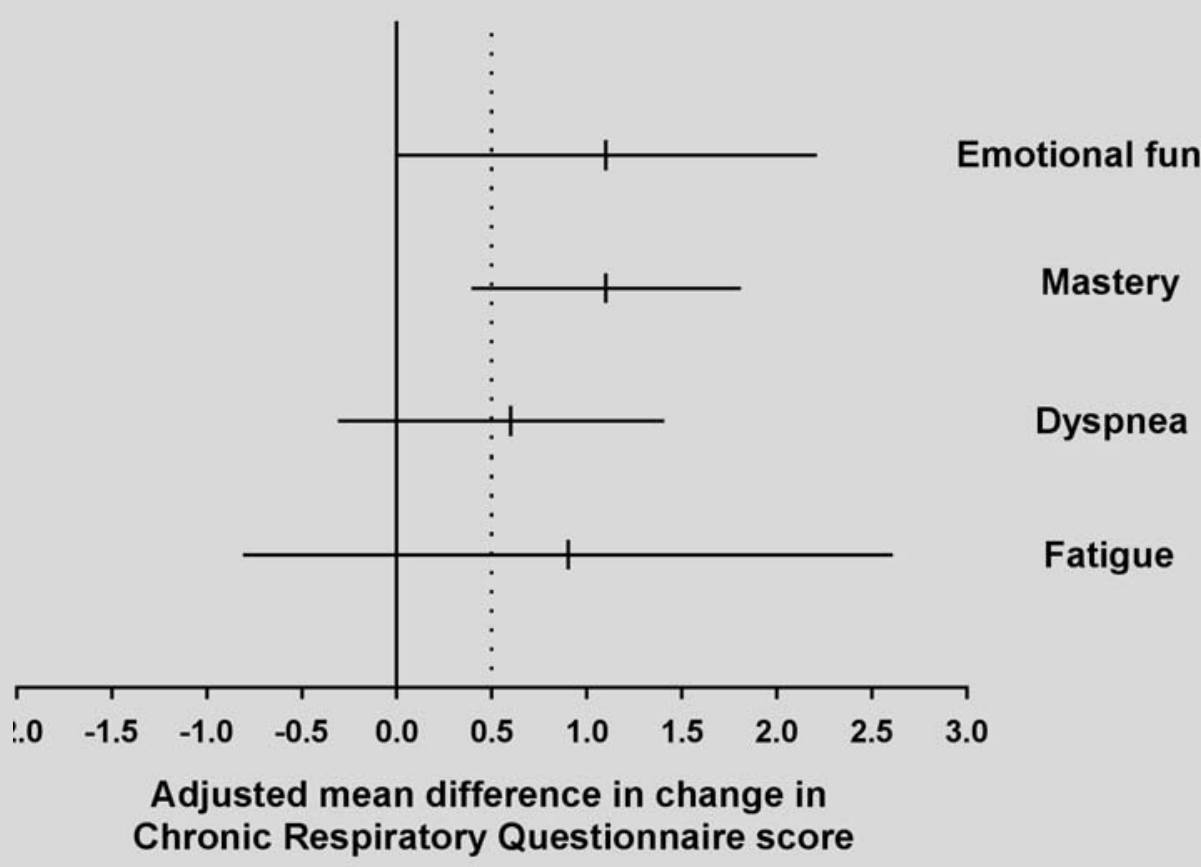

Fig. 3. - Adjusted mean differences in CRQ scores between the two study groups and associated $95 \%$ confidence intervals. The vertical (dashed) line represents the minimal clinically important difference, that is the smallest difference in score that patients view as important and that would mandate a change in the patients' management [16]

\section{Geriatric Depression Scale}

In the per-protocol analysis, the GDS score improved in those treated with Paroxetine (withingroup difference at final follow-up: $-5.4 ; p=0.04$ ) but not in those in the control group (within-group difference: $-1.8 ; \mathrm{p}=0.6$ ). The adjusted mean dif- ference between the two groups at final follow-up was not significant (3.5; 95\% CI: -4.9 - 12.0).

\section{Adverse effects}

Overall, the side effects did not appear to be more important in the treatment than in the control 
Table 3. - Side effects

\begin{tabular}{lcc}
\hline Side effects & Paroxetine $(\mathbf{n}=\mathbf{1 2})$ & Placebo $(\mathbf{n}=\mathbf{1 1})$ \\
\hline Constipation & 2 & 0 \\
Dizziness & 0 & 2 \\
Flatulence & 0 & 1 \\
Taste perversion & 1 & 0 \\
Nausea & 2 & 1 \\
Headache & 2 & 0 \\
Dry mouth & 1 & 1 \\
Somnolence & 5 & 2 \\
Tremor & 2 & 0 \\
\hline
\end{tabular}

group (table 3). Only one patient dropped out from the trial because of side effects related to Paroxetine (figure 1). Paroxetine was not associated to any worsening of respiratory symptoms.

\section{Discussion}

The results of this small randomized trial indicated that the emotional responses of patients with severe, oxygen-dependent COPD may improve following antidepressant drug therapy when significant depressive symptoms are present. Howev- er, the interpretation of the results is limited by a high refusal rate to participate as well as a high drop-out rate after randomization.

This trial followed our study showing that significant depressive symptoms and depression are highly prevalent in patients with severe COPD on LTOT [3]. In this survey, we found strong evidence that depression is under-recognized and under-treated in this group of patients. This was in agreement with other studies suggesting that, in elderly patients with chronic medical diseases, unrelated disorders are indeed under-treated [21]. Following this study, we expected a large number of patients to be recruited for our trial. Although 105 were eligible, only 23 of them accepted to be randomized, the primary reasons of refusal including a wish not to change medication, not to take placebo, or not to take an "experimental" medication. These reasons have repeatedly been cited as barriers to patient participation in randomized controlled trials [22]. This high rate of refusal underlined the difficulties in conducting experimental studies in frail, elderly and emotionally distressed patients.

According to the GDS, all our patients had "significant depressive symptoms". Its administration was not followed by a full psychiatric interview. Therefore, it remains uncertain whether our patients met the definition of "major depression",

Table 4. - Antidepressant drug therapy in COPD: summary of the published randomized controlled trials

\begin{tabular}{|c|c|c|c|c|}
\hline Study & Study design & Intervention & Measurement instruments & Results \\
\hline Gordon et al. [26] & $\begin{array}{l}\text { Randomized } \\
\text { double-blind } \\
\text { cross-over trial } \\
\left(n=6^{*}\right)\end{array}$ & $\begin{array}{l}\text { Desipramine } \\
\text { vs. placebo } \\
\text { (8-week periods) }\end{array}$ & $\begin{array}{l}\text { Depression: Beck Depression } \\
\text { Inventory and Zung Self-Rating } \\
\text { Depression Scale }\end{array}$ & $\begin{array}{l}\text { Both treatments (Desipramine } \\
\text { and placebo) led to a } \\
\text { significant improvement } \\
\text { in depression scores }\end{array}$ \\
\hline Light et al. [27] & $\begin{array}{l}\text { Randomized } \\
\text { double-blind } \\
\text { cross-over trial } \\
(\mathrm{n}=9 *)\end{array}$ & $\begin{array}{l}\text { Doxepine vs. } \\
\text { placebo } \\
\text { (6-week } \\
\text { periods) }\end{array}$ & $\begin{array}{l}\text { Exercise capacity: } 12-\min \\
\text { walk test; Depression: Beck } \\
\text { Depression Inventory; } \\
\text { Anxiety: Spielberger's } \\
\text { State-Trait Anxiety Inventory }\end{array}$ & $\begin{array}{l}\text { No significant differences } \\
\text { in either exercise capacity } \\
\text { or psychological scores } \\
\text { was observed }\end{array}$ \\
\hline Borson et al. [28] & $\begin{array}{l}\text { Randomized } \\
\text { double-blind } \\
\text { parallel groups } \\
\text { trial } \\
\left(\mathrm{n}=30^{*}\right)\end{array}$ & $\begin{array}{l}\text { Nortriptyline } \\
(\mathrm{n}=13) \text { vs. } \\
\text { placebo } \\
(\mathrm{n}=17) \\
(12 \text {-week } \\
\text { duration) }\end{array}$ & $\begin{array}{l}\text { Exercise capacity: } 12-m i n \\
\text { walk test; Dyspnea: Pulmonary } \\
\text { Function Status and Dyspnea } \\
\text { Questionnaire; Depression: } \\
\text { Hamilton Depression Rating } \\
\text { Scale; Anxiety: Patient-Rated } \\
\text { Anxiety Scale }\end{array}$ & $\begin{array}{l}\text { Nortriptyline treatment } \\
\text { was accompanied by } \\
\text { improvements in anxiety, } \\
\text { certain respiratory symptoms, } \\
\text { and day-to-day function; } \\
\text { physiological measures } \\
\text { remained unaffected. } \\
\text { The clinical significance } \\
\text { of these changes is unknown } \\
\text { (see text) }\end{array}$ \\
\hline Ström et al. [29] & $\begin{array}{l}\text { Randomized } \\
\text { double-blind } \\
\text { parallel groups } \\
\text { trial } \\
\left(\mathrm{n}=26^{*}\right)\end{array}$ & $\begin{array}{l}\text { Protriptyline } \\
(\mathrm{n}=14) \text { vs. } \\
\text { placebo } \\
(\mathrm{n}=12) \\
(12 \text {-week } \\
\text { duration) }\end{array}$ & $\begin{array}{l}\text { Dyspnea: 6-point scale } \\
\text { developped for the purpose } \\
\text { of the study; Quality of life: } \\
\text { Sickness Impact Profile; } \\
\text { Anxiety and depression: } \\
\text { Mood Adjective Checklist; } \\
\text { Hospital Anxiety and Depression } \\
\text { Scale }\end{array}$ & $\begin{array}{l}\text { No significant difference } \\
\text { in the quality-of-life } \\
\text { questionnaire scores in either } \\
\text { of the two treatment groups; } \\
\text { neither proptriptyline nor } \\
\text { placebo had any impact } \\
\text { on the dyspnea score }\end{array}$ \\
\hline
\end{tabular}

* number of patients who completed the trial. 
"dysthymic disorder" or "adjustment disorder with depressed mood" according to the Diagnostic and statistical manual of mental disorders classification [23]. However, the appropriate diagnostic threshold of depression mandating therapy is still a matter of debate [24]. For instance, in a prospective cohort study of patients with coronary heart disease, patients with major depression and those with minor depression were significantly more functionally impaired than those with no depression. The major and minor depression group did not differ significantly [25]. This study suggested that minor depression may be particularly important in patients with co-morbid medical illnesses.

Previous small placebo-controlled trials of antidepressant drug therapy in patients with COPD [26-29] did not demonstrate significant treatment effect on depression or quality of life (table 4). Several reasons may explain this situation. First, in two studies $[26,29]$, depressive symptoms were not required for inclusion. Second, the validity of most health-status measure instruments used in these trials has not been clearly ascertained beforehand, and those that were used often consisted of generic or case-finding instruments unlikely to be able to detect small but clinically important changes over time [30]. This remark represents a strong argument against the conduct of a metaanalysis of the randomized trials of antidepressant drug therapy in COPD. Despite a very small number of patients, our finding of large and statistically significant differences in the "emotional function" and "mastery" domains of the CRQ indicated that Paroxetine is highly active in secondary depression. The mean differences in the "dyspnea" and "fatigue" domains of the CRQ exceeded the minimal clinically important difference but were not statistically significant. This results from the small sample size and the consequent lack of power of our trial.

When an antidepressant drug is prescribed, the most important potential side effect to consider in patients with severe COPD is respiratory depression. No report on this effect of the new selective serotonin-reuptake inhibitors is currently available. The antidepressant drugs are however a class of medication with little effect of the ventilatory drive [31]. Other concerns with antidepressant drugs in patients with COPD are related to their potential cardiovascular side effects. The results of two studies in depressive patients and healthy men provided strong evidence that therapeutic doses of Paroxetine lack any important haemodynamic and electrophysiological effects [32].

Who should manage depression in COPD? Many family physicians will be comfortable in properly assessing depression, in prescribing antidepressant drugs and in offering psychological support. Although pulmonary physicians usually focus on the physiological aspects of the disease, they are usually involved in the patients' reference to respiratory rehabilitation programs in which a psychological assessment is usually conducted. From a survey of pulmonary rehabilitation programs in Canada conducted in 1998, social work- ers and psychologists were involved in the interdisciplinary team delivering rehabilitation in respectively $43 \%$ and $9 \%$ of the out-patient programs surveyed [8]. Referral to a psychiatrist is indicated when: (1) the diagnosis of depression is unclear; (2) the depression is refractory to pharmacological and/or non-pharmacological therapy; (3) the choice of anti-depressant drug is complicated by the concurrent medication; (4) the patient presents with suicidal ideation [33]. Thus, the proper management of depressive symptoms or overt depression in severe COPD depends on an enhanced collaboration among health care providers.

\section{References}

1. Lacasse Y, Brooks D, Goldstein RS. Trends in the epidemiology of chronic obstructive pulmonary disease in Canada, 1980-95. Chest 1999; 116: 306-13.

2. Cooper CB. Determining the role of exercise in patients with chronic pulmonary disease. Med Sci Sports Exer 1995; 27: 147-57.

3. Lacasse Y, Rousseau L, Maltais F. Prevalence of depressive symptoms and depression in patients with severe oxygen-dependent chronic obstructive pulmonary disease. J Cardiopulm Rehabil 2001; 21: 80-6.

4. American Thoracic Society. Pulmonary rehabilitation 1999. Am J Respir Crit Care Med 1999; 159: 1666-82.

5. Casaburi R, Patessio A, Ioli F, et al. Reductions in exercise lactic acidosis and ventilation as a result of exercise training in patients with obstructive lung disease. Am Rev Respir Dis 1991; 143: 9-18.

6. Maltais F, LeBlanc P, Simard C, et al. Skeletal muscle adaptation to endurance training in patients with chronic obstructive pulmonary disease. Am J Respir Crit Care Med 1996; 154: 442-7.

7. Lacasse $\mathrm{Y}$, Brosseau L, Milne S, et al. Respiratory rehabilitation in chronic obstructive pulmonary disease (Cochrane review). In: the Cochrane Library, Issue 2, 2002. Oxford: Update Software.

8. Brooks D, Lacasse Y, Goldstein RS. Pulmonary rehabilitation programs in Canada: national survey. Can Respir J 1999; 6: 55-63.

9. Yesavage JA, Brink TL. Development and validation of a geriatric depression screening scale: a preliminary report. J Psychiat Res 1983; 17: 37-49.

10. Brink TL, Yesavage JA, Lum O, et al. Screening tests for geriatric depression. Clin Gerontologist 1982; 1: 37-43.

11. Yesavage JA. Depression in the elderly. Postgrad Med 1992; 91: 255-61.

12. Covino NA, Dirks JF, Kinsman RA, et al. Patterns of depression in chronic illness. Psychother Psychosom 1982; 37: 144-53.

13. Gunasekara NS, Noble S, Benfield P. Paroxetine: an update of its pharmacology and therapeutic use in depression and a review of its use in other disorders. Drugs 1998; 55: 85-120.

14. Guyatt GH, Berman LB, Townsend $\mathrm{M}$, et al. A measure of quality of life for clinical trials in chronic lung disease. Thorax 1987; 42: 773-8.

15. Lacasse Y, Wong E, Guyatt GH. A systematic overview of the measurement properties of the Chronic Respiratory Questionnaire. Can Respir J 1997; 4: 131-9.

16. Jaeschke R, Singer J, Guyatt GH. Measurement of health status: ascertaining the minimal clinically important difference. Controlled Clin Trials 1989; 10: 407-15.

17. McHorney CA, Ware JE Jr, Raczek AE. The MOS 36item short form health survey (SF-36): II. Psychometric and clinical tests of validity in measuring physical and mental health constructs. Med Care 1993; 31: 247-63. 
18. Leplege A, Ecosse E, Verdier A, et al. The French SF36 Health Survey: translation, cultural adaptation and preliminary psychometric evaluation. J Clin Epidemiol 1998; 51: 1013-23.

19. Lacasse Y, Guyatt GH. Methodology of therapeutic trials in COPD. In: Similowski T, Whitelaw WA, Derenne JP (eds.). Clinical management of chronic obstructive pulmonary disease. New York, Marcel Dekker Inc. 2002; 255-85.

20. Hopman WM, Towheed T, Anastassiades T, et al. Canadian normative data for the SF-36 health survey. Can Med Assoc J 2000; 163: 265-71.

21. Redelmeier DA, Tan SH, Booth GL. The treatment of unrelated disorders in patients with chronic medical diseases. N Engl J Med 1998; 338: 1516-20.

22. Ross S, Grand A, Counsell C, Gillespie W, Russell I, Prescott R. Barriers to participation in randomised controlled trials: a systematic review. J Clin Epidemiol 1999; 52: 1143-56.

23. American Psychiatric Association. Diagnostic and statistical manual of mental disorders IV. Washington DC, American Psychiatric Association, 1994.

24. Regier DA, Kaelber CT, Rae DS, et al. Limitations of diagnostic criteria and assessment instruments for mental disorders. Inmplications for research and policy. Arch Gen Psychiatry 1998; 55: 109-15.

25. Sullivan M, LaCroix A, Russo J, Swords E, Sornson M, Katon W. Depression in coronary heart disease: what is the appropriate diagnostic threshold? Psychosomatics 1999; 40: 286-92.
26. Gordon GH, Michiels TM, Mahutte CK, et al. Effect of Desipramine on control of ventilation and depression scores in patients with severe chronic obstructive pulmonary disease. Psych Res 1985; 15: 25-32.

27. Light RW, Merrill EJ, Despars J, et al. Doxepin treatment of depressed patients with chronic obstructive pulmonary disease. Arch Intern Med 1986; 146: 1377-80.

28. Borson S, McDonald GJ, Gayle T, et al. Improvement in mood, physical symptoms, and function with nortriptyline for depression in patients with chronic obstructive pulmonary disease. Psychosomatics 1992; 33: 190-201.

29. Ström K, Boman G, Pehrsson K, et al. Effect of proptyline, $10 \mathrm{mg}$ daily, on chronic hypoxaemia in chronic obstructive pulmonary disease. Eur Respir J 1995; 8: 425-9.

30. Lacasse Y, Wong E, Guyatt GH, Goldstein RS. Healthstatus measure instruments in chronic obstructive pulmonary disease. Can Respir J 1997; 4: 152-64.

31. Steen SN. The effects of psychotropic drugs on respiration. Pharm Ther 1976; 2: 717-41.

32. Warrington SJ, Lewis Y. Cardiovascular effects of antidepressants: studies of Paroxetine in healthy men and depressed patients. Int Clin Psychopharmacol 1992; 6 [suppl.]: 59-64.

33. Nault D, Siok MA, Borycki E, Melanson D, Rousseau L, Lacasse Y. Psychosocial considerations in COPD. In: Bourbeau J, Nault D, Borycki E (eds.). Comprehensive management of chronic obstructive pulmonary disease. Hamilton, BC Decker Inc, 2002: 215-44.

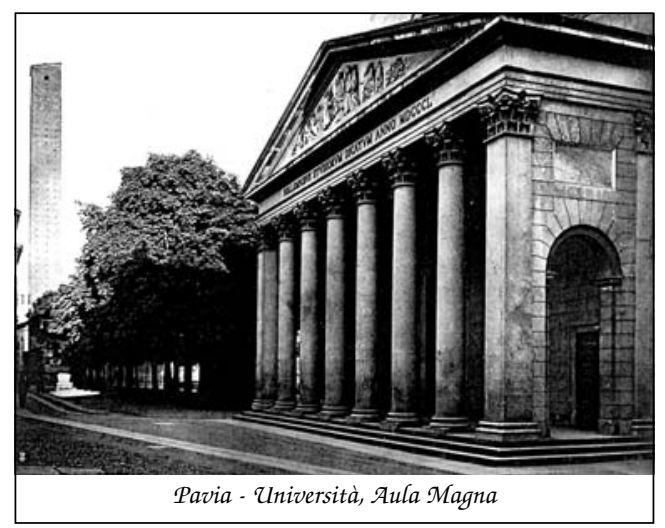

